\title{
Context of NBIC-Technologies Development: Institutions, Ideology and Social Myths
}

\section{Evgeny G. Kamensky}

\author{
Candidate of Sciences (Sociology), Southwest State University (SWSU), Kursk, Russian Federation \\ kamensky80@mail.ru
}

\section{Doi:10.5901/mjss.2015.v6n6s4p181}

\begin{abstract}
The article presents the author's viewpoint on the basic characteristics of the socio-cultural context of the development of convergent technologies in the modern world. The main aspects of this contextual area are the states of social institutions, ideology and social myths in conditions of institutional competition. It is proved in the article that modern convergent technologies in addition to the status of scientific and technological products have their own social and spiritual status in society as anideologeme of technocracy. Being an urgent issue of modern ideology, the problem of technological breakthrough is used by institutional subjects in their own interests, legitimizes their claim to power, and is turned into fetish. The relevance of understanding the whole complexity of social aspects of NBIC-technologies is proved by increasingly frequent using of this abbreviation withthe letter 'S'(Socio) added to it: NBICS.
\end{abstract}

Keywords: Converging technologies, the sociology of technology, social contexts of technology, scientific and technological progress, social institutions, ideology, social myths.

\section{Introduction}

NBIC-convergence as a particularly urgent issue encourages the widest possible number of representatives of scientific community sharing the ideas of humanistic knowledge to address the topic and fill research-oriented media space with the typical declarative statements in the form of articles, oral presentations and similar forms. There are a few substantial, especially practice-oriented, or at least empirically proved researches in relation to the total volume of representation of this issue in the communicative exchange of the scientific community, both inside the community and outside it.

This situation illustrates the gap between NBIC range of specific problems and live social context, which is a complex (in its structural, functional, normative, and ethical aspects)environment producing and consuming the object under study, taking into account its multidimensional nature and its own representation, illustrated with broad discussion in media space not only scientific one but also political, economic, in everyday practices, however. What is important is that the focus of public attention is concentrated on the problems of social and humanitarian consequences of convergent technologies challenges, but the issues of social and causal factors of their occurrence, existence and development from the contextual position of the situation in socio-cultural environment fall out of it. Meanwhile, hi-tech, in general, and NBIC-technologies, in particular, are as much a product of spiritual and material culture of the society, like any other ideological and material objects produced by mankind.

Taking into account the abovementioned, an incomplete understanding of socio-cultural context of new technologies development, especially its value-oriented, normative, and regulative aspects, in modern scientific communication is considered one of the central challenges of our study. That is, we mean the totality of real social conditions of a particular social and cultural scope. Of course, these characteristics are ambivalent with respect to the process of the development of technogenic progress of the society and go far beyond the challenges of its social ability of being approved/disapproved, accepted/rejected and the like. We are primarily interested in the contours and the structure of these contexts, as well as the referential completeness of the content, with regard to NBIC-technologies development; we believe the true values of this content can be revealed only on the basis of sociologically-oriented system methodology. This opinion is based, primarily, on the fact that understanding of the actual mechanisms of social processes in the system 'society' is the core subject is sociology.

\section{Research Methodology}

Conceptually systematizing opportunities of philosophical approach are essential for the separation from abstract empiricism and speculative interpretations of the results of sociological research which are often observed nowadays. In 
this case, the very thought experiment is necessary for addressing the issues of the presence/absence of meaningful relationships between latent and empirically presentative processes and processes explained on the basis of scientific social and humanitarian methods. Currently, these aspects of knowledge, and, most importantly, research methodology, are being developed actively among the progressive representatives of the scientific community; these ideas are represented in system universalist approaches, Synergetics, Memetics and the like (Haken, 2012; Dawkins, 1976) which are considered today less marginalized and more approved against the background of mass enthusiasm for inter- and transdisciplinary knowledge in all the branches of social sciences and humanities.

Consequently, it is possible to indicate at least two basic issues which lie in the necessity to describe the very problem of the study both in a live social context and in the selection of adequate methodology and branch analytical tools for this description. The scope, in which the research will be carried out, most likely will be presented by the macrolevel in descriptive terms because the most common identifiable trends are presented in it, as well by the meso-level (in this case, institutional) in analytical terms, because it is necessary 'to get off' in the hierarchical structure of the sociocultural system from cultural and social binding parameters of the system to the very locations of their functional representation to provide a conceived idea with the result which is really identified in the society. That is it is necessary to pass from order parameters to the control parameters. Lower levels of subordination are not included directly in the subject area of our work, since, currently, the degree of objectivity of linear determination of subject behavior by environmental factors is cast under justified doubts in the society. Human will may be the reason for this. According to K. Mainzer, nonlinear dynamics can generate complex states not forecasted for distant horizon, that is, a restriction for computability is observed (Mainzer, 2011).

In addition, it must be emphasized that the structural functionalism approach (Parsons, 1961) and other classical approaches are not used by us in their back-to-basics branch form but are geared to the operational objectives of the study.

Synergistic principles concerning both methodology and defining the ontology of objects are considered to be the most efficient ones in our research. As a goal of the study we attempt to develop and describe a system-parametric model of social contexts of technological convergence. A successful example of using the concept of order parameters in sociological aspect is found in the works of $\mathrm{H}$. Haken (Haken, 1996).

Certain aspects of complex forecasting and modelling in relation to the state and the development of technogenic and other transformations of human environment and human being future are being developed (see, eg, Benjamin et al., 2001; Bostrom, 2002; Kirk, 2001; Kurzweil, 1999; Waldeman, 1994; Kamensky E, 2014; Boev E. \& Kamensky E., 2015).

Deserve special attention of authors highlight the concept of allowing the technosphere, as an integral part of the noosphere M. Heidegger (Heidegger, 2002), K. Popper (Popper, 1972).

Questions of scientific and technical progress and attempts to build a scientific picture of the engaged J. Bernal (Bernal, 1970), P. Davis (Davis, 1977).

About riskogennom factor of technological development say U. Beck (Beck, 1995), G. Behmann (Behmann, 2012), D. Bell (Bell, 1973), A. Toffler (Toffler, 2010). Of particular interest from the standpoint of the proposed research project is the work of H. Haken (Haken, 1985), E.H. Knyazeva (Knyazeva, 2005), S.P. Kurdyumov (Kurdyumov, 2001), S.P. Kapitza (Kapitsa, 2010), and others who are considering the idea of unsustainable development of society from the perspective of synergy.

\section{Results}

Speaking of convergent technologies in sociological aspect, it is necessary to try and see them through the lens of the basic elements of social and cultural matrix, i.e. in terms of norms and values. Speaking in relation to society as a 'unity composed of individuals' objectively, in the form of social facts (Durkheim, 1982), value and norm structures are fixed in the mass and individual consciousness as a-priori ideologemes intrinsic to a particular type of society at a certain stage of historical process. Based on this statement, we consider the ideological space of modern society as the referential field for studying the stated problem in which it is possible to find answers to the question concerning the true social image, status and significance of NBIC issues.

Let us explain what we mean. NBIC-technologies become actual to the society, not only as a kind of abstract and independent tools of transformative activity of the mankind, but also as an ideologeme in the structure of the modern worldview, of the mass consciousness. Such ideologeme cannot emerge spontaneously, as well as it cannot be fixed in the form of ideological pattern. This is a characteristic feature only of a certain type of social ideology, which is referred to as technocracy at present. Nevertheless, technocratism is also not an independent value ideologeme and plays an instrumental role in the ideology of humanitarian mankind progress. In particular, if we pay attention to all the socio- 
cultural acquisitions of humanity having absolutely empirically reified character in the form of real technologies, it's hard not to notice their complete dependence on scientific and technological progress (STP). In this case, technocracy is legitimized by social policy depending directly on the level of technical and technological complex of the state, and also determining the level of the domination of geopolitical subjects on the world stage due to industrial and economic superiority.

It is important to note here that 'NBIC-convergence' is often used with the letter ' $\mathrm{S}$ '(Socio) added to it: NBICS. Our study is an attempt to search for the meaning of this supplement. Taking into account the above considerations, we believe that NBIC-problematics, being an urgent topic of technical and technological development, intrinsically, acts also as a converging ideologeme in socio-phenomenological sense, representing as pace of intersection of different ranges of values (Schutz, 1967) of mass and individual consciousness. We believe that such statement is possible because today NBICS-convergence is an independent goal-setting area of social development, which also forms a system of values and-norms, the matrix of which can be filled in with different social codes of church, politics, science, and other relatively autonomous institutional structures of the society. As a result, obviously, there is a competition between these institutional subjects for the right to determine the instrumental status of these new technologies on the basis of their own ideological and regulatory grounds. Of course, it is more appropriate here to speak exactly not about NBIC, but about technocracy and NBIC-technologies are modern culmination of it.

We can model examples of NBIC-problematics adaptation for the vector of institutional concerns:

1. Church: using NBIC is a tool of God.

2. Science as atheistic rationalism: NBIC is a tool against God.

3. Policy: NBIC is a tool of geopolitical struggle and national superiority.

4. Economy: NBIC is a tool for economic competitiveness, possible monopoly to determining vectors of the global economy.

It is possible to continue this list. Everything depends on a specific institutional subject; but it is obvious that the $\mathrm{NBIC}$ serves as a common space of inter section of different ranges of values at the institutional level of social life.

It is important to understand the fact that there is always a possibility to use one institutional subject as a tool by another institutional subject in achieving the highest level of social and cultural influence in the society. In the modern world this often manifests itself not in the form of aggressive domination, but as a hidden parasitizing or a symbiosis in the form of consensus or compromise. The only question is who and at what expenses is willing to participate tactically and strategically in this.

If you believe in the theory of 'global conspiracy' and the like, as well as if you do not believe in them, we consider this statement is true on the grounds that, despite the typed features of people's thinking and behavior in relation to the outlined topic, there are ideological and behavioral orientations described above. Such statements can be proved on the basis of the empirical sociological content analysis of media space, but this is beyond the scope of our study. However, what is obvious is that the ideological independence of technocracy is under question, and NBIC is a modern dominant of technocratic orientation in various forms of social institutions today.

The structure of the problem will be developed in a more detailed way further focusing on its macro-characteristics, describing them as particular clarifications where possible.

For example, another important condition for understanding socio-cultural aspects of NBIC-issues is the necessity to take into account the ideology function of creating social myths of legitimizing importance for institutional struggle. In such cases, these myths are an integrative link for all cultural and contextual structures and this link also acts a converging element for various social forces in the society, a sort of 'assemblage point' of the general context of goalsetting.

The necessity of considering this aspect is based on the fact that NBIC-issues along with other fetishes of technocracy is included in the institutional ideology, which claims to 'capture' the orienting functions of consciousness not only of its own electorate but also of the part that goes beyond its direct institutional coverage. In the context of approval of NBIC-convergence topic in ideological space (though, currently, even its opponents are working at its promotion), each institutional agent proposes his own ideologemes focused on the specifics of value and normative characteristics of his electoral group.

The role of media space increases in this process; today, it focuses mostly on maintaining narrow-minded and amateurish approach of an average consumer in the assessment of scientific and technological progress (NTP) achievements. But along with a direct informative function of the media environment, the important characteristic is its political and economic orientation, making from macro-communicators (as subjects of mass communication) a kind of 'proxies' of certain ideology who reproduce social myths broadcasting information desired for mass consciousness and promoting the formation of a sustainable pattern of recipient worldview. 
Despite the real and the hypothetical possibility of lobbying for media perspectives by tools of any institutional and other meta-subjects, the state and political institutions have the most advantageous position in this process. Even by the example of a single ideological platform of the state and the church (outside different ontological platforms of their ideology in a secular state) represented in secular states and evident in a number of examples (the president in the church, the priest in the army, etc.), the trends of adapting institutional ideology to a national one are evident in the conditions of'strong power'. In this case, only the forms of mythologems differ, because they have different motivating grounds mediated by institutional characteristics. The core thing is fight for the electorate (which is understood in a broader sense than politics) as a reserve for maintaining ideologically-orienting status of the institute and it remains the same.

In the conditions of a 'strong power it is more beneficial for some institutional subjects to cooperativize with it and in doing so to maintain and increase their own electorate. Atheists supporting the President can 'accept faith' being guided by 'the idol'; some holders of religious belief will support the President seeing that the Church supports his policy and loyalty of the head of state to the Church. An even more striking example is acts legitimizing homosexuality, euthanasia and other forms of social relations which contradict with traditional religious dogmas. As a result, purely religious grounds will be pushed off to the periphery of the common ideology of development one of the leading factors of which today is the development and implementation of 'high' technologies (in a number of priority ones is NBIC) and innovations in the context of the post-industrial liberalism.

Social policy of the state serves as a connecting and harmonizing link between political, religious and other institutional dogmas, because it meets both religious ideas of kindness and ideas of implementing constitutional democracy in politics and ideas of science 'in the name of humanity'. As a result, the disagreements are recognized as non-essential in the whole process of 'higher goals' implementation.

Perhaps it is the institutional social myths that stand for memetic carrier of technocratic ideology, where it is often latent as a meme (Dawkins, 1976) and is observed in the social codes-ideologemes of 'better tomorrow' as an implied priori condition of achieving them in the context of the modern 'high-tech' world. In this case, a formula of thinking according to which thinking about human progress we automatically see it through technogenic attributes (an example of this is a more legitimized in science term 'technoscience') and ways of achieving it. This phenomenon is widespread, though certainly there are socio-cultural loci with other worldview stereotypes but their influence becomes less noticeable on the macro-scale.

The most important thing is that for the modern ideology of social development technocratic ideologemes in their lead status must serve as legitimation of establishing meritocracy in the society but the social reality demonstrates the processes of oligarchy strengthening and the archaization of the principles of organization of power, the spread of the ideology of 'consumer society' (Krupkin, 2009; Arshinov 2011). In scientific periodicals the current state of social and political system is described as a corporate-corruption economy, oligarchic-capitalism shadow (Nikolaeva, 2005), which already semantically contain the mentioned characteristic features of social and cultural environment.

\section{Conclusion}

Thus, if current trends continue developing, the post-industrialism, despite replicated contemporary expectations and projections, may take decadence rather than technologically-deterministic progressive humanitarian form. In this case, the latest technologies and NBIC-convergence as well foreseeable future with still poorly observable consequences contribute to stabilization of the stagnation and degradation conditions, because they are developed and implemented in a corresponding ideology of consumerism and global cultural unification and are included in the tool set of legitimation of non-progressive goals of the human future, working to achieve the results of political, economic and ideological superiority. More spreading facts of industrial espionage, information warfare, and different kinds of unfair competition in the struggle for resources as an instrument of power against the background of problems of hunger, disease mortality, and the like are far from the high ideals of human development and prove this conclusion. At the same time there are even more global forecasts (Bostrom, 2002).

On a larger scale, scientific and research activity serves as an instrument of this struggle, losing its traditional independence in setting such objectives as attainment of truth, improvement of life, alleviating sufferings. Thus, that this is why we consider that science is being sacralized in the same way as religious meanings do, forming in the public worldview an idea of its incomprehensibility for an everyman, the possibility of setting the goals of its development and using its results only by privileged politicians and economists with their own criteria assessment. Perhaps, it is understanding of this fact that encourages the emergence of various converged forms of appealing (civil, scientific, etc.) for the development of the humanitarian examination assessment of scientific, engineering and technology development. 
Thus technological convergence is the stimulus for social and cultural convergence. The only problem is that if the current situation continues its existence for a period of time, there will be nobody but sacralized politics who will be able to conduct such examination assessment. The circle will be closed. All that remains is to hope for the prophecies of the coming technological singularity, though they do not guarantee the arrival of 'The Strugatsky brothers' Worlds' and do not cancel meritocratic dictatorship in a new stratification the prophecies about which also exist.

\section{Funding}

The research is financed by Russian Science Foundation, project No 15-18-10013 «Social-anthropological dimensions of convergent technologies», Southwest State University (Kursk), Institute of Philosophy RAS (Moscow).

\section{References}

Arshinov V.I. (2011). Innovation, Tradition and Archaic as the Valuable Components of Culture in its Complexity-Synergistic Dimension. Personality. Culture. Society, 13 (2), 79-89. (in Russian).

Beck, U. (1995). Risk Society. Beverly Hills, CA.

Behmann, G. (2012). Social and philosophical and methodological problems of the address with technological hazards in modern society. Questions of Philosophy, 7, 120-132. (in Russian).

Bell, D. (1973). The Coming of Post-Industrial Society: A Venture in Social Forecasting. New York.

Benjamin, D.K. et al. (2001). Individuals' Estimates of Risks of Death: Part II - New evidence. Journal of Risk and Uncertainty, 22(1), 3557.

Bernal, J.D. (1970). Sozialgeschichte der Wissenschaften. Reinbek bei Hamburg.

Boev, E. \& Kamensky, E. (2015).An Innovation Civilization in the Context of the Anthroposphere Crisis of the Technogenic Society. Asian Social Science, 11(4), 328-335. doi: 10.5539/ass.v11n4p328

Bostrom, N. (2002). Existential Risks. Analyzing Human Extinction Scenarios and Related Hazards. Journal of Evolution and Technology, 9(1).

Davis, P. (1977). Space and time in the modern universe. Cambridge University Press.

Dawkins, R. (1976). The Selfish Gene. New York: Oxford University Press, 352 p.

Durkheim, E. (1982). The rules of the sociological method. Tr. by W.D. Halls. New York: The Free Press, 265 p.

Haken, G. (1985). Sinergetika: Hierarchies of not stability in self-organizing systems and devices. Moskow. (in Russian).

Haken, H. (1996). Sinergetics as a Bridge and Social Sciences. In: Evolution, Order and Complexity. London; N.Y.: Routledge, pp. 234248.

Haken, H. (2012). Synergetics: An Introduction. Berlin; Heidelberg; New York; Tokyo: Springer-Verlag, 408 p.

Heidegger, M. (2002). Die Technik und die Kehre. Klett-Cotta: Stuttgart.

Kamensky, E. (2014). Instrumental Theoretical and Methodolodgical Construct of a Conception of the Human Environment. Pensee, 76(11), 9-21.

Kapitsa, S.P. (2010). Paradoxes of growth: Laws of development of humanity. Moskow. (in Russian).

Kirk, K.M. (2001). Natural Selection and Quantitative Genetics of Life-History Traits in Western Women: A Twin Study. Evolution, 55(2), $432-435$

Knyazeva, E.N. (2005). Synergetrics basis. Synergetic mirovideniye. Moskow. (in Russian).

Krupkin, P.L. (2009). Archaism - the dominant trend of social changes in Russia. The Scientific Expert, 7-8, 86-88. (in Russian).

Kurdyumov, S. P. (2001). Sinergetika and new mirovideniye. Synergetrics and culture. Moscow pp. 4-9. (in Russian).

Kurzweil, R. (1999). The Age of Spiritual Machines: When computers exceed human intelligence. New York: Viking.

Mainzer, K. (2010). Calls of Complexity in XXI Century. Questions of Philosophy, 10, 84-89. (in Russian).

Mainzer, K. (2011). Interdisciplinarity and Innovation Dynamics. On Convergence of Research, Technology, Economy, and Society. Poiesis and Praxis, 7(4), 275-289. doi: 10.1007/s10202-011-0088-8

Nikolaeva, H.S. (2005). Domestic and Foreign Economic Coercion: the Place of the Archaic in the Modern Economy and Social Practice. Sociology of Power, 4, 81-95. (in Russian).

Parsons, T. ([1937] 1961). The Structure of Social Action. New York: The Free Press of Glencoe.

Popper, K. (1972). Objective Knowledge: An Evolutionary Approach. London: Oxford University Press.

Prigogine, I. (1989). The Philosophy of Instability. Futures, 21(4), 396-400.

Prigogine, I. \& Stengers, I. (1984). Order Out of Chaos: Man's new dialogue with nature. New York: Bantam Books Inc., 349 p.

Schutz, A. (1967). The Phenomenology of the Social World / Trans, by G. Walsh, F. Lehnert. Evanston: Northwestern University Press.

Toffler, A. (2010). The Third Wave. Moskow. (in Russian).

Waldeman, M. (1994).Systematic Errors and the Theory of Natural Selection. The American Economics Review, 84(3), $482-497$. 